УДК 341

DOI https://doi.org/10.17308/vsu.proc.law.2021.2/3406

\title{
ОБЕСПЕЧЕНИЕ ОНЛАЙН-ДОСТУПА К ТОВАРАМ И УСЛУГАМ В РАМКАХ ВНУТРЕННЕГО РЫНКА ЕВРОПЕЙСКОГО СОЮЗА
}

\author{
Е. В. Постникова \\ Национальный исследовательский университ \\ "Высшая школа эконолики" \\ Поступила в редакцию 19 января 2021 г.
}

\begin{abstract}
Аннотация: анализируются меры, принилаелье на уровне Европейского союза (EC) в иелях обеспечения онлайн-доступа $к$ товарал и услугал как неотьеллемой составляющей внутреннего рынка и единого ицфрового рынка в частности. Делонстрируется последовательность, колплексность и скоординированность действий институтов ЕС для повышения эоббективности правового регулирования в собере электронной торговли. Опьт ЕС может быть полезен для Российской Федераиии как активного участника межгосударственных объединений экономической интеграиии, наприлер, Евразийского эконолического союза.

Ключевые слова: Европейский союз, право Европейского союза, внутренний рынок Европейского союза, единый ицфровой рынок Европейского союза, электронная торговля, свобода движения товаров, свобода предоставления услуг.
\end{abstract}

\begin{abstract}
European Union (EU) level to ensure online access to goods and services as an integral part of the internal market and the single digital market, in particular. Demonstrates the consistency, complexity and coordination of the actions of EU institutions to improve the efficiency of legal regulation in the field of electronic commerce. The experience of the EU can be useful for the Russian Federation as an active participant in interstate economic integration organizations, for example, the Eurasian Economic Union.

Key words: European Union, European Union law, internal market of the European Union, single digital market of the European Union, electronic commerce, freedom of movement of goods, freedom to provide services.
\end{abstract}

Европейский союз (далее - ЕС) является примером для других межгосударственных объединений, экономической интеграции в том числе, в связи с его постоянным развитием, которое как началось с создания Сообществ в 1950 -е гг. ${ }^{1}$, так и не только не прекращается, но и носит по-

1 Учитывая правопреемство ЕС и Европейского сообщества на основании Лиссабонского договора (см.: Treaty of Lisbon amending the Treaty on European Union and the Treaty establishing the European Community, signed at Lisbon, 13 December 2007 // Official Journal of the European Union C 306/01, 17.12.2007). См. также: Мюллер-Графбб П.-К. Лиссабонский договор в системе первичного права Европейского союза // Право. Журнал Высшей школы экономики. 2008. № 1.

(C) Постникова Е. В., 2021 
стоянный характер и, естественно, только набирает обороты, учитывая потребности развития межгосударственных отношений ${ }^{2}$ (в том числе в связи с техническим прогрессом). И этот процесс постоянного рефрормирования права ЕC, или иначе - динамичного развития, выгодно отличает его от многих других международных организащий ${ }^{3}$.

Одно из главных достижений ЕС составляет внутренний рынок. Для обеспечения должного внутреннего рынка необходимо устранить как государственные препятствия, так и препятствия, создаваемые частными лицами (продавцами товаров и поставщиками услуг). Создание внутреннего рынка провозглашено в п. 3 ст. 3 Договора о Европейского союзе (далее - ДЕС $)^{4}$. Определение внутреннего рынка дается в п. 2 ст. 26 Договора о функционировании Европейского союза (далее - ДФЕС). Основная суть свобод внутреннего рынка раскрывается в ДФЕС ${ }^{5}$ Интересно мнение, что в ДФЕС косвенно отражена иерархия между свободами внутреннего рынка и что свобода движения товаров превалирует над другими свободами ${ }^{6}$ Это, в частности, объясняется с точки зрения эволюции права общего рынка и в дальнейшем - внутреннего рынка. Действительно, прежде всего, разрабатывался механизм реализации именно этой свободы, и впоследствии некоторые его элементы стали применяться и к остальным свободам (например, императивные требования общего интереса ${ }^{7}$. Определение услуг в ДФЕС дается опосредованно через объекты иных свобод, т. е. по остаточному принципу. Конечно, либерализация торговли товарами проходила проще и быстрее, чем перемещения объектов иных экономических свобод, в частности в силу их особенностей, заинтересованности государств в контроле над ними. Анализируя положения ДФЕС и иных правовых актов ЕС, можно усмотреть некую иерархию между свободами внутреннего рынка. Однако даже свободное движение товаров продолжает вызывать интенсивные дискуссии, поскольку оно находится на пересечении сложного выбора между государственным

${ }^{2}$ Считаем целесообразным сослаться на работу Ю.С. Ромашева, посвященную праву международных обычаев, в которой справедливо подчеркивается необходимость соответствия практики закономерностям общественного развития и потребностям развития межгосударственных отношений (см.: Ролашев Ю. С. Право международных обычаев. М., 2020. С. 53). И правда, требование прогрессивности необходимо и для обычной, и для договорной нормы международного права.

${ }^{3}$ Cm.: Pescatore P. Le droit de l'integration. Emergence d'un phénomène nouveau dans les relations Internationales selon l'expérience des Communautés Européennes, Bruylant. 2005.

${ }^{4}$ Consolidated Versions of the Treaty on European Union and the Treaty on the Functioning of the European Union / / Official Journal. 2008.

${ }^{5}$ В частности, это соответственно ст. 34 и 35, 45, 49, 56 и 63.

${ }^{6}$ Cм.: Boutayeb C. Droit matériel de l'Union Eropéenne. Libertés de mouvement, espace de concurrence et secteur publique. $4^{\mathrm{e}}$ édition. LDGJ, Lextenso. 2017. P. 27.

${ }^{7}$ Cm.: Case 120/78 Rewe-Zentral AG v Bundesmonopolverwaltung für Branntwein (Cassis de Dijon) [1979] ECR 649. 


\section{Вестник ВГУ. Серия: Право}

регулированием и свободой рынка, с одной стороны, а также полномочиями ЕС и государств - с другой 8 .

Свобода движения товаров и свобода предоставления услуг были закреплены еще в Договоре об учреждении Европейского экономического сообщества 1957 г. ${ }^{9}$ и составляли элементы общего рынка. Тогда и речи не было о торговле товарами и услугами в сети «Интернет». Конечно, учредительные договоры ЕC не содержали положений, непосредственно посвященных электронной торговле и ее особенностям, и последние внесенные в них изменения этого не коснулись. Данное исследование посвящено именно изучению права ЕC в сфрере электронной торговли, особенно за последние пять лет. Разумеется, в правовую основу реализации онлайн-торговли товарами и услугами включены нормы о свободе движения товаров и свободе предоставления услуг, закрепленные в учредительных договорах ЕC, а также актах вторичного права, из сферы действия которых не исключена электронная торговля. Но раскрываться в данной статье содержание свобод внутреннего рынка не будет, поскольку не это является целью исследования ${ }^{10}$.

Внутренний рынок должен эволюционировать таким образом, чтобы полностью интегрировать цифровую трансформацию. И, как подчеркивает А. Н. Пилипенко, масштабы и последствия современного этапа информатизации общества носят революционный характер ${ }^{11}$. Развитие цифрровых технологий стало фрактором цифровизации права ${ }^{12}$. Не будем забывать и о такой цели деятельности ЕС, которая раскрывается в п. 3 ст. 3 ДЕС. В частности, речь идет об обеспечении устойчивого развития Европы на основе сбалансированного экономического роста и стабильности цен, конкурентоспособной рыночной экономики, а главное - Союз должен способствовать научно-техническому прогрессу. По мнению

П. А. Калиниченко и С. Ю. Кашкина, для достижения этих целей Союз

일 создает внутренний рынок, т. е. создание последнего является средством

${ }^{8}$ A Companion to European Union Law and International Law / Editor(s): Dennis Patterson, Anna Södersten. - John Wiley \& Sons, Inc., 2016. P. 205-216. (Maduro

254 M.P., de Sousa P.C. The Free Movement of Goods).

${ }^{9}$ Treaty establishing the European Economic Community (1957). URL: http://eurlex.europa.eu/en/treaties/dat/11957E/tif/TRAITES_1957_CEE_1_EN_0001.tif

10 O содержании свобод внутреннего рынка см., например: Barnard $C$. The substantive law of the EU. The four freedoms. First edition. Oxford University Press, 2007 ; Dony M. Droit de l'Union Européenne. Troisième édition revue et augmentée. Edition de l'Université de Bruxelles: Bruxelles. 2008, 2010 ; European Union law. Cases and materials / Damian Chalmers, Gareth Davies and Giorgio Monti. Second edition. Cambridge University Press, 2010.

${ }^{11}$ См.: Пилипенко А. Н. Франция : к цифровой демократии // Право. Журнал Высшей школы экономики. 2019. № 4. С. 186.

${ }^{12}$ См.: Понкин И. В., Редькина А. И. Искусственный интеллект и право интеллектуальной собственности // Интеллектуальное право. Авторское право и смежные права. 2018. № 2. С. 35-44. 
достижения целей $\mathrm{EC}^{13}$. Сегодня трансграничная электронная торговля обладает большим потенциалом, вносящим существенный вклад в интеграционные процессы в рамках внутреннего рынка ЕС. В 2020 г. (год распространения Covid-19) как никогда люди почувствовали незаменимость цифровых технологий, прежде всего сети «Интернет», в частности для приобретения товаров и услуг.

В связи с возросшей востребованностью и значимостью электронной торговли возросла и необходимость в правовом регулировании этой сферы отношений. Еще в 2000 г. была принята Директива № 2000/31 14 о некоторых правовых аспектах услуг информационного общества и особенно электронной торговли на внутреннем рынке, в которой ставилась цель содействовать должному функционированию внутреннего рынка путем обеспечения свободного движения услуг информационного общества между государствами-членами. За последние 20 лет объемы электронной торговли существенно выросли, в том числе за счет новых сфер, и стала очевидна необходимость в принятии новых правовых актов.

Поскольку электронная торговля представляет один из объектов регулирования в рамках Единого циорового (электронного) рынка, то последний обойти вниманием никак нельзя, а следовательно, и принятую в 2015 г. Стратегию Единого цифрового рынка для Европы ${ }^{15}$ (далее - Стратегия). В 2017 г. Европейская комиссия (далее - Комиссия) опубликовала Среднесрочный обзор ${ }^{16}$ об исполнении Стратегии для единого цифрового рынка. Н. С. Ревенко объясняет необходимость разработки Стратегии тем, что «мировая экономика быстро становится цифровой, а информационно-коммуникационные технологии (далее - ИКТ) уже являются основой для инноваций и современных экономических систем, меняя методы работы и людей, и компаний» ${ }^{17}$. Стратегия имеет целью упразднение препятствий в рамках единого цифррового рынка, лишающих граждан EC возможности извлекать преимущества от выбора товаров и услуг, а предприятий - в полной мере участвовать в будущем развитии сектора цифровых технологий. Высказывается точка зрения, что Стратегия затрагивает множество различных областей политики с довольно расплы-

${ }^{13}$ Право Европейского союза : учебник для вузов / под ред. С. Ю. Кашкина. 4-е изд., перераб. и доп. М., 2019. С. 21.

${ }^{14}$ Directive 2000/31/EC of 8 June 2000 on certain legal aspects of information society services, in particular electronic commerce, in the Internal Market ('Directive on electronic commerce') // OJL 178, 17.07.2000, p. 1-16.

${ }^{15}$ Commission staff working document «A Digital Single Market Strategy for Europe - Analysis and Evidence». Accompanying the document "A Digital Single Market Strategy for Europe». COM(2015) 192 final. Brussels, 06.05.2015 SWD(2015) 100 final.

16 Communication from the Commission on the Mid-Term Review on the implementation of the Digital Single Market Strategy. A Connected Digital Single Market for All. \{SWD(2017) 155 final\} Brussels, 10.05.2017 COM(2017) 228 final.

${ }^{17}$ Ревенко Н. С. Европейский союз на пути к единому цифровому рынку // Мир новой экономики. 2016. № 2. С. 7. 
вчатыми и поверхностными предложениями ${ }^{18}$. Однако с такой позицией нельзя согласиться, разве что частично.

Обеспечение онлайн-доступа потребителей и бизнес-структур к товарам и услугам в рамках всего ЕС явилось одним из трех приоритетных направлений по становлению единого цифрового рынка ЕС. В качестве двух других Комиссия выделила создание необходимых и равных условий для развития цифровых сетей и инновационных услуг и максимизацию потенциального роста цифровой экономики.

В рамках данной статьи представляет несомненный интерес исследование сектора электронной торговли, инициированное Комиссией одновременно с принятием самой Стратегии. Окончательный отчет с результатами по итогам его проведения был представлен в 2017 г. $^{19}$ Исследование было осуществлено во исполнение ст. 17 Регламента 1/2003 о применении правил конкуренции, закрепленных в ст. 81 и 82 Догово$\mathrm{pa}^{20}$. Проведенное Комиссией исследование сектора электронной торговли охватило наиболее продаваемые товары. В итоге Комиссия пришла к выводу, что за последнее десятилетие произошло увеличение объемов электронной торговли. И это оказало существенное влияние на стратегию компаний по распространению своей продукции, а также на поведение потребителей. Однако Комиссия пришла также к выводу, что существует целый ряд проблем при реализации права конкуренции ЕС, среди которых выборочное распределение, ограничения продажи и рекламы в сети «Интернет», включая географические ограничения и ограничения в сорере ценообразования. По итогам проведенного исследования Комиссия заключила, что необходимо целенаправленно применять нормы права конкуренции к таким деловым практикам, которые способны оказать негативное влияние на трансграничную торговлю, а также активировать диалог с властями государств-членов по вопросам последовательного применения права конкуренции ЕС в сфере электронной торговли.

Итак, для реализации возможностей, которые может предоставить единый цифровой рынок, в Стратегии была поставлена цель повысить доступность к рынку товаров и услуг в сети «Интернет». Иными словами, следовало обеспечить при помощи быстрых и своевременных действий готовность внутреннего рынка к цифровой эре. Это было бы возможно, если устранить препятствия на пути становления единого цифрового рынка, которые, в частности, тормозят трансграничную электронную торговлю.

${ }^{18}$ Cм.: Mette $M$. The European Digital Single Market Strategy and Related Copyright Law Implications: The Status Que. URL: https://www.whitecase.com/publications/article/european-digital-single-market-strategy-and-related-copyright-law-implications (дата обращения: 27.12.2020).

${ }^{19}$ Report from the Commission. Final report on the E-commerce Sector Inquiry. $\operatorname{COM}(2017) 229$ final. Brussels, 10.05.2017 SWD(2017) 154 final.

${ }^{20}$ Council Regulation (EC) No 1/2003 of 16 December 2002 on the implementation of the rules on competition laid down in Articles 81 and 82 of the Treaty // Official Journal L 1, 04.01.2003, p. 1. Отметим, что на момент принятия Регламента действовал Договор об учреждении Европейского сообщества. Учитывая положения Лиссабонского договора, речь идет о ст. 101 и 102 ДФЕС. 
Для достижения этой цели предлагалось принять целый ряд мер. Для упорядочения материала в данной статье было решено использовать классификацию мер, разработанную Комиссией и представленную в Стратегии Единого цифрового рынка.

Прежде всего, в рамках Единого цифрового рынка при ведении электронной торговли права и обязанности продавиов и их покупателей должны регулироваться общим сводом правил и принципов. Конечно, право ЕС на момент принятия Стратегии содержало нормы, гарантирующие соблюдение прав потребителей вне зависимости от способа продажи товаров и услуг. Например, Директива 2011/83 о правах потребителей ${ }^{21}$ полностью гармонизировала некоторые аспекты прав потребителей и договорного права, применимого к электронной торговле (в частности, доконтрактная информация для потребителей) ${ }^{22}$. Однако если говорить о других областях, то на уровне ЕС существовала минимальная гармонизация.

Как отмечает Бутаеб, этот подход позволяет гармонизировать некоторые элементы в рамках одного сектора благодаря закреплению в директиве, а другие аспекты остаются в сфере компетенции национальных властей ${ }^{23}$. Однако характеристика, данная автором, не отражает сути этого подхода, которая заключается в том, что речь идет о разработке минимальных стандартов на уровне ЕС, представляющих собой нижний предел, который является объектом полной гармонизации и порой может быть установлен на достаточно высоком уровне ${ }^{24}$. В решении по делу C-84/94 Working time ${ }^{25}$ Суд ЕС объяснил, что минимальные стандарты не означают наиболее низкие требования и наименьший уровень защиты, установленный в государствах-членах. Таким образом, государства-члены вправе принимать более строгие меры в отношении своих товаров и услуг по сравнению со стандартами, установленными в актах $\mathrm{EC}^{26}$.

Так, Директива 1999/44 о некоторых аспектах продажи потребительских товаров и связанных с ними гарантий ${ }^{27}$ содержала минимальные гармонизированные нормы о правовых средствах защиты в случае не-

${ }^{21}$ Directive 2011/83/EU of the European Parliament and of the Council of 25 October 2011 on consumer rights, amending Council Directive 93/13/EEC and Directive 1999/44/EC of the European Parliament and of the Council and repealing Council Directive 85/577/EEC and Directive 97/7/EC of the European Parliament and of the Council // OJ L 304, 22.11.2011, p. 64-88.

${ }^{22}$ Статья 3 Директивы о сфере ее действия.

${ }^{23}$ См.: Boutayeb C. Op. cit. P. 115.

${ }^{24}$ Следует иметь в виду, что термин «минимальная гармонизация» включает на языке оригинала (например, английском) слово «minimum», a не «minimal».

${ }^{25}$ Case C-84/94 United Kingdom of Great Britain and Northern Ireland v Council of the European Union [1996] ECR I-05755. Par. 56.

${ }^{26}$ Cм. также: Case 382/87 R. Buet [1989] ECR 01235; Case C-11/92 Gallaher [1993] ECR I-03545.

${ }^{27}$ Directive 1999/44/EC of 25 May 1999 on certain aspects of the sale of consumer goods and associated guarantees // OJ L 171, 07.07.1999, p. 12-16. 


\section{Вестник ВГУ. Серия: Право}

соответствия материальных товаров ${ }^{28}$ договору купли-продажи. Но на уровне ЕС отсутствовали гармонизированные нормы о средствах правовой защиты в случае несоответствия договору цифрового или электронного продукта (показ фольмов или спортивное вещание в сети «Интернет», облачные сервисы (услуги $\left.{ }^{29}\right)$. Таким образом, в подобных областях существовало различное правовое регулирование на национальном уровне, и Комиссия предлагала предпринять действия по устранению такой фрагментации.

Еще одно предложение Комиссии было связано с внесением поправок в Регламент 2006/2004 о сотрудничестве национальных властей, ответственных за исполнение законов о защите прав потребителей ${ }^{30}$, так как исполнение должно быть более быстрым, гибким, последовательным и эфрфективным. Для этого, в частности, требовалось уточнить и расширить полномочия компетентных органов, улучшить координацию их деятельности и создать общеевропейскую платформу разрешения споров.

В 2017 г. данный Регламент утратил свою силу в связи с принятием Регламента 2017/2394 ${ }^{31}$ с таким же названием, который вступил в силу 17 января 2020 г. Новые нормы нацелены на то, чтобы упростить для государств-членов защиту прав потребителей при совершении покупок при помощи сети «Интернет». Предмет регулирования нового Регламента полностью совпадает с предметом регулирования предыдущего (ст. 1). В Регламенте закреплен перечень минимальных прав в сфрере расследования и принудительных действий, которыми должна быть наделена каждая компетентная власть (ст. 10). Так, на основании ст. 9 теперь могут быть удалены сайты или учетные записи в социальных сетях, в рамках которых были зафиксированы противоправные действия.

Немаловажную роль играет и Регламент 1024/2012 об административном сотрудничестве посредством Информационной системы внутреннего рынка ${ }^{32}$. Эта система используется для сотрудничества между компетентными властями государств-членов и между последними и Комиссией, необходимого для имплементации правовых актов ЕС по вопросам фрункционирования внутреннего рынка. Подобное сотрудничество включает обмен персональными данными. Конечно, Регламент имеет

${ }^{28}$ Скорее здесь имеется в виду не товар по смыслу права внутреннего рынка $\mathrm{EC}$, а продукт в более широком понимании. Конечно, «материальный товар» это тавтология.

${ }^{29}$ Cloud services - англ. яз.

${ }^{30}$ Regulation (EC) No 2006/2004 of 27 October 2004 on cooperation between national authorities responsible for the enforcement of consumer protection laws (the Regulation on consumer protection cooperation) // OJ L 364, 09.12.2004, p. 1-11.

${ }^{31}$ Regulation (EU) 2017/2394 of 12 December 2017 on cooperation between national authorities responsible for the enforcement of consumer protection laws and repealing Regulation (EC) No 2006/2004 // OJ L 345, 27.12.2017, p. 1-26.

${ }^{32}$ Regulation (EU) No 1024/2012 of 25 October 2012 on administrative cooperation through the Internal Market Information System and repealing Commission Decision 2008/49/EC ('the IMI Regulation') // OJ L 316, 14.11.2012, p. 1-1. 
ограниченную сферу действия, обозначенную в Приложении. Например, он применяется в отношении Сети сотрудничества по вопросам защиты потребителей ${ }^{33}$ на основании Регламента 2017/2394 (о котором речь была чуть выше) и системы Solvit ${ }^{34}$, а также Директивы 2006/123 по услугам на внутреннем рынке. Ю. М. Юмашев характеризует Solvit как внесудебную процедуру решения проблем, связанных с недолжным применением государствами-членами правового регулирования внутреннего рынка ${ }^{35}$.

Кроме того, в мае 2019 г. были приняты две директивы о новых правилах в сфере договоров в цифровой сфере на основе предложений Комиссии, сделанных в 2015 г. Первая - Директива 2019/770 о некоторых аспектах, касающихся договоров поставки цифрового контента и предоставления цифровых услуг ${ }^{36}$. Вторая - Директива 2019/771 о некоторых аспектах, касающихся договоров по продаже товаров ${ }^{37}$. Последняя директива, в частности, отменяет упомянутую выше Директиву 1999/44.

Целями Директив соответственно является обеспечение надлежащего фрункционирования внутреннего рынка, предоставляя высокий уровень защиты прав потребителей, устанавливая общие нормы в отношении некоторых требований, касающихся:

- договоров между продавцами ${ }^{38}$ и потребителями по поставке цифррового контента и цифровых услуг, в частности нормы о соответствии цифррового контента или цифровых услуг условиям договора; о средствах правовой защиты в случае отсутствия такого соответствия или невыполнения поставки, об условиях использования этих средств, а также о модифрикации цифрового контента или цифровой услуги;

- договоров купли-продажи (между продавцами ${ }^{39}$ и потребителями), в частности нормы о соответствии товаров условиям договора, о средствах правовой защиты в случае отсутствия такого соответствия, об условиях использования этих средств и о коммерческих гарантиях.

Таким образом были созданы нормы, закрепляющие более четкие права потребителей, подпадающие под сферу действия Директив. Примером может послужить ситуация, когда цифровой контент или услуга не соответствуют условиям договора, и тогда потребитель вправе получить

${ }^{33}$ Consumer Protection Cooperation Network (CPC) - англ. яз.

${ }^{34}$ Commission Recommendation 2013/461/EU of 17 September 2013 on the principles governing SOLVIT // OJ L 249, 19.09.2013, p. 10-15.

35 См.: Юлашев Ю. М. Правовое регулирование европейского внутреннего рынка // Моск. журнал междунар. права. 2013. № 3 (91). С. 163.

${ }^{36}$ Directive (EU) 2019/770 of the European Parliament and of the Council of 20 May 2019 on certain aspects concerning contracts for the supply of digital content and digital services // OJ L 136, 22.05.2019, p. 1-27.

${ }^{37}$ Directive (EU) 2019/771 of the European Parliament and of the Council of 20 May 2019 on certain aspects concerning contracts for the sale of goods, amending Regulation (EU) 2017/2394 and Directive 2009/22/EC, and repealing Directive 1999/44/ EC // OJ L 136, 22.05.2019, p. 28-50.

\footnotetext{
38 «Trader» - англ. яз.

39 «Seller» - англ. яз.
} 


\section{Вестник ВГУ. Серия: Право}

оговоренные в договоре контент или услугу, а также пропорциональное уменьшение цены или вправе прекратить действия договора (ст. 14 Директивы 2019/770).

До принятия этих директив на уровне ЕС не существовало норм, касающихся цифрового контента и цифровых услуг ненадлежащего качества. Естественно, по этой причине имела место фррагментация правового регулирования в данной сфере. Гармонизация норм о цифрровых договорах должна привести, с одной стороны, к сокращению расходов продавцов и служить стимулом для развития трансграничной торговли, а с другой - к повышению доверия потребителей к этим объектам торговли. Обеспечение доступа потребителей к цифрровому контенту и цифровым услугам, а также упрощение для бизнеса поставки цифрового контента и цифровых услуг может способствовать развитию цифровой экономики Союза и стимулированию общего роста.

В ноябре 2019 г. была принята еще Директива 2019/2161, направленная на повышение качества обеспечения соблюдения и модернизации норм EC в сфрере защиты прав потребителей ${ }^{40}$. Она уже вступила в силу и должна быть имплементирована в нащиональные законодательства государств-членов до 28 ноября 2021 г. Например, теперь государства-члены будут обязаны закреплять нормы о санкциях, применимых в случае нарушения национальных положений, принятых в соответствии с настоящей Директивой, а также предпринимать все возможные действия, необходимые для обеспечения их выполнения. Предусмотренные санкции должны быть эффрективными, пропорциональными и оказывающими сдерживающее воздействие. Нововведением также являются, в частности, требования к продавцам при снижении цены. Так, в любом объявлении о снижении цены должна быть указана предыдущая цена,

применяемая продавцом в течение определенного периода до примене일 ния снижения цены.

Еще одним комплексом мер в целях обеспечения онлайн-доступа к товарам и услугам выступают меры в отношении услуг по трансграничной доставке посылок. Несомненно, это направление является неотъемлемой частью электронной торговли. Однако информация о рын-

260 ке подобных услуг фррагментирована и национальные власти обладают лишь ограниченным мандатом по контролю за предоставлением услуг по трансграничной доставке товаров. Комиссия обещала повысить транспарентность применительно к уровню цен и улучшить контроль за трансграничными поставками. В 2018 г. был принят Регламент 2018/644 об услугах по трансграничной доставке посылок ${ }^{41}$, который направлен на

${ }^{40}$ Directive (EU) 2019/2161 of 27 November 2019 amending Council Directive 93/13/EEC and Directives 98/6/EC, 2005/29/EC and 2011/83/EU as regards the better enforcement and modernisation of Union consumer protection rules // OJ L 328, 18.12.2019, p. 7-28.

${ }^{41}$ Regulation (EU) 2018/644 of 18 April 2018 on cross-border parcel delivery services // OJ L 112, 02.05.2018, p. 19-28. 
улучшение данных услуг в части: надзора за предоставлением услуг; прозрачности тарифов и оценки тарифов на некоторые услуги с целью выявления тех, которые неоправданно высоки; информирования потребителей об услугах, предоставляемых продавцами ${ }^{42}$. Это три ключевые цели данного Регламента. В частности, из норм Регламента вытекает обязанность поставщиков услуг по доставке посылок предоставлять информацию о ценах, которая позволит национальным регулирующим органам лучше контролировать поставщиков и их субподрядчиков. Новые нормы должны привести к большей прозрачности цен и развитию конкуренции. Это позволит потребителям проще найти более дешевый способ отправить посылку в другое государство - член ЕС. Регламент содержит перечень данных, которые компании, предоставляющие почтовые услуги, должны сообщать ежегодно национальным властям. Интересно, что речь идет о минимальной гармонизации, суть которой была раскрыта выше.

Следующий комплекс мер, предложенный Комиссией, касался территориальных ограничений и геоблокировки ${ }^{43}$ в собере торговли товарали и услугали. Естественно, единый рынок предполагает, что потребители пользуются всеми преимуществами электронной торговли. Однако часто онлайн-магазины, учрежденные в другом государстве - члене ЕС, не продают определенные товары или услуги и цифровой контент или используют специальные сайты в зависимости от государства нахождения потребителя, часто на разных условиях. Один из наиболее встречающихся видов рыночной практики и территориальных ограничений, выделенных Комиссией, это геоблокировка, которая представляет собой практику продавцов товаров и услуг по блокированию или ограничению доступа потенциального покупателя из другого государства - члена ЕС к веб-сайту или определенному контенту, отказу в регистрации, созданию сложностей с регистрацией или автоматическому перенаправлению на веб-сайты, ориентированные на другие государства-члены. Возможна также и ситуация, когда продавец применяет различные общие условия доступа к своим товарам и услугам, условия оплаты в отношении покупателей в зависимости от их гражданства, места постоянного проживания или учреждения. В сфрере розничного предоставления услуг ограничение свобод внутреннего рынка может выражаться в ограничении поставщиком возможности розничных продавцов покупать товары у кого и откуда они хотят через границы.

В упомянутом выше Отчете Комиссии по итогам исследования сектора электронной торговли 2017 г. геоблокировка была названа среди проблем при реализации права конкуренции ЕС. По результатам одного из исследований, проведенных Комиссией, было выявлено, что только 37 \% веб-сайтов в действительности позволяли потребителям из других госу-

${ }^{42}$ Регламент вступил в силу на двадцатый день с момента официального опубликования и применяется с 22 мая 2018 г.

${ }^{43}$ Geo-blocking - англ. яз. 
дарств - членов ЕС при заполнении электронной формы для покупки каких-либо товаров достичь последнего этапа, предшествующего вводу данных банковской карты ${ }^{44}$. Самый высокий процент блокировки был в секторе электрических бытовых приборов - 86 \%. Интерес представляет то, что геоблокировка наиболее распространена в соглашениях, касающихся телесериалов (74 \%), фрильмов (66 \%) и спортивных событий (63 \%), а менее всего в соглашениях по другим категориям цифрового контента, таким как музыка (57 \%), детское телевидение (55 \%), неигровое телевидение (51\%) и новости $(24 \%)^{45}$.

Усилия, предпринимаемые государствами для устранения искусственной сегментации рынка в зависимости от места жительства потребителя, могут быть нейтрализованы препятствиями, создаваемыми частными сторонами, которые сегментируют внутренний рынок вдоль национальных границ. Это тем более проблематично в контексте внутреннего рынка в ситуации, когда соответствующие законы государств-членов недостаточно ясны, единообразны и эфрфективны для преодоления таких препятствий. Министр Болгарии при председательстве Болгарии в Совете ЕС (Лилиана Павлова) подчеркнула значимость цифровой экономики и отметила, что прекращение практики «геоблокировки» означает увеличение выбора товаров и услуг и, следовательно, более выгодные сделки для потребителей, а также больше возможностей для предпринимателей ${ }^{46}$.

В 2018 г. был принят Регламент 2018/302 о противодействии необоснованной геоблокировке и иным формам дискриминации покупателей в зависимости от гражданства, места постоянного проживания и учреждения ${ }^{47}$. В Регламенте закрепляется запрет дискрилинаиии покупателей на основании гражданства, места постоянного жительства и места учреждения в отношении: доступа к онлайн-интерфейсам (например, 이 веб-сайтам) электронной торговли; доступа к товарам и услугам; условий оплаты; соглашений о пассивных продажах.

Очередной мерой для обеспечения доступа к объектам электронной торговли, бесспорно, является улучшение доступа и использование ииябрового контента, зашищенного авторскил правол. Как справедливо отметил А. А. Карцхия, расширение сфер трансграничного оборота това-

${ }^{44}$ Geo-blocking in the EU. European Commission. URL: https://www.consilium. europa.eu/en/infographics/geo-blocking/ (дата обращения: 25.12.2020).

${ }^{45}$ Final report on the E-commerce Sector Inquiry. COM(2017) 229 final.

${ }^{46}$ Geo-blocking: Council adopts regulation to remove barriers to e-commerce. URL : http://www.consilium.europa.eu/en/press/press-releases/2018/02/27/geo-blocking-council-adopts-regulation-to-remove-barriers-to-e-commerce/ (дата обращения: 25.12.2020).

${ }^{47}$ Regulation (EU) 2018/302 of 28 February 2018 on addressing unjustified geo-blocking and other forms of discrimination based on customers' nationality, place of residence or place of establishment within the internal market and amending Regulations (EC) No 2006/2004 and (EU) 2017/2394 and Directive 2009/22/EC // OJ L 60I, 02.03.2018, p. 1-15. 
ров, услуг и капиталов в совокупности с применением современных технологий в условиях цифрровой экосистемы фрормируют новый правовой ландшафт и расширяют сфреры действия права интеллектуальной собственности $^{48}$. Система защиты авторских прав в ЕС представляет собой ключевой элемент культурной, социальной и технологической среды, а также цифровой экономики ${ }^{49}$. Однако трансграничному распространению цифрового контента, к которому относятся видео- и аудиофрайлы, игры и текст, препятствует недостаток сетей высокой пропускной способности и наличие большого числа цифровых материалов, защищенных авторскими правами. В. Л. Энтин обосновывал необходимость рефрормы тем, что онлайн-услуги предоставления доступа к контенту создали условия для трансграничного использования произведений, объектов смежных прав в сфере культуры, развлечений, науки и образования, которые не вписываются в традиционные модели регулирования на уровне национального законодательства ${ }^{50}$. Комиссия стремится разработать современные правовые рамки в сфрере авторского права, которые будут способствовать трансграничной доступности цифррового контента. Итак, пересмотренные нормы авторского права содержатся, в частности, в принятых в 2019 г. директивах: Директива 2019/790 об авторском праве и смежных правах в рамках Единого цифрового рынка ${ }^{51}$ и Директива 2019/789, касающаяся правил о реализации авторского права и смежных прав, применимых к некоторым онлайн-трансляциям вещательных организаций и ретрансляциям теле- и радиопрограмм ${ }^{52}$. Целями этих директив является обеспечение: во-первых, большей трансграничной доступности онлайн-контента; во-вторых, более широких возможностей по использованию материалов, защищенных авторским правом, в образовании, исследованиях и культурном наследии; в-третьих, улучшения фрункционирования рынка авторских прав. Интересно мнение В. И. Еременко, что положения Директивы 2019/789 будут распространяться на российские издания, доступные на территории ЕС ${ }^{53}$.

${ }^{48}$ См.: Карихия A. A. Облачные технологии : правовой аспект // Рос. юрид. журнал. 2018. № 6. С. 163.

${ }^{49}$ European Patent Office and the Office for Harmonization in the Internal Market, Intellectual property rights intensive industries: contribution to economic performance and employment in the European Union, Industry-Level Analysis Report, 2013.

${ }^{50}$ См.: Энтин В. Л. Справедливое вознаграждение как драйвер реформы авторского права в цифровой среде // Современное право. 2019. № 3. С. 53-54.

${ }^{51}$ Directive (EU) 2019/790 of the European Parliament and of the Council of 17 April 2019 on copyright and related rights in the Digital Single Market and amending Directives 96/9/EC and 2001/29/EC // OJ L 130, 17.05.2019, p. 92-125.

${ }^{52}$ Directive (EU) 2019/789 of 17 April 2019 laying down rules on the exercise of copyright and related rights applicable to certain online transmissions of broadcasting organisations and retransmissions of television and radio programmes, and amending Council Directive 93/83/EEC // OJ L 130, 17.05.2019, p. 82-91.

${ }^{53}$ См.: Ереленко В. И. Директива Евросоюза о реформе авторского права в рамках единого цифрового рынка // ИС. Авторское право и смежные права. 2019. № 11. C. 21-22. 
Наконец, еще один комплекс мер, который касается процедур уплаты НДС при трансграничных онлайн-продажах. В ЕС каждая продажа товара или предоставление услуг облагается НДС, который составляет от 17 до 27 \% от цены в зависимости от государства-члена. Государства пришли к консенсусу, что НДС должен взиматься в государстве потребления товара или услуги. А если речь идет о трансграничной торговле онлайн, то соблюдение норм об НДС становится еще более сложным и обременительным для предпринимателей. Как подчеркивает Комиссия, с тех пор как НДС взимается в стране потребителя, в соответствии с законодательством последней применяются разные нормы об НДС и, естественно, задействованы различные налоговые органы. В Стратегии также отмечается, что продавец, поставляющий материальный товар потребителю в другое государство-член, должен регистрироваться и оплачивать налог в каждом государстве. Но ситуация иная в отношении электронных услуг, поскольку с 1 января 2015 г. НДС начисляется и оплачивается по правилам страны нахождения потребителя. В 2014 г. Экспертная группа Комиссии по налогообложению в сфере цифровой экономики предложила распространить принцип взимания налога в государстве получения всех товаров и услуг и особенно рекомендовала, чтобы управление единой электронной регистрацией и системой уплаты НДС, осуществляемое государством поставщика, распространилось на трансграничную торговлю ${ }^{54}$. Было также рекомендовано отменить исключения на уплату НДС при импорте небольших партий товара из третьих стран и установить единый порог налогообложения на уплату НДС стартапами.

Говоря о доступе к товарам и услугам, нельзя не упомянуть принятую в 2019 г. Директиву 2019/882 о требованиях доступности товаров и услуг ${ }^{55}$, и государства должны будут следовать указанным в ней мерам с 28 июня 2025 г. Заметим, что сфера действия этой директивы достаточно узкая. В Директиве перечисляются товары и услуги, доступность которых охватывается ее сферой действия. Так, это услуги, обеспечивающие доступ к аудиовизуальным медиауслугам; электронные книги и специальное программное обеспечение; услуги электронной торговли; веб-сайты и электронные билеты в сфере воздушных, автобусных, железнодорожных и водных пассажирских транспортных услуг (но есть исключения).

Итак, за последнее десятилетие роль электронной торговли в экономике ЕС резко возросла, что повысило необходимость совершенствования ее правового регулирования. Ключевую роль здесь играет Европейская комиссия. Потенциал роста электронной торговли в ЕС еще не полностью использован. Стратегия Единого цифрового рынка для Европы направлена на комплексное устранение основных препятствий на пути

${ }^{54}$ European Commission, Report from the Commission Expert Group on Taxation of the Digital Economy, 28.05.2014. URL: https://ec.europa.eu/taxation_customs/ sites/taxation/files/resources/documents/taxation/gen_info/good_governance_matters/ digital/report_digital_economy.pdf (дата обращения: 05.10.2020).

${ }^{55}$ Directive (EU) 2019/882 of 17 April 2019 on the accessibility requirements for products and services // OJ L 151, 07.06.2019, p. 70-115. 
развития трансграничной электронной торговли в ЕС, чтобы раскрыть этот потенциал. В связи с быстрым развитием сектора электронной торговли усугубились существующие и появились новые проблемы, в том числе в сфрере конкуренции. Для создания эффрективно фрункционирующего Единого цифрового рынка чрезвычайное значение имеет единообразное толкование правил конкуренции ЕС применительно к деловой практике на рынках электронной торговли. Иначе это будет создавать существенные препятствия для деятельности компаний в нескольких государства - членах ЕС. В ходе проводимого исследования было интересно проследить, на сколько выполнимы задачи, поставленные Комиссией в Стратегии в рамках данного направления деятельности. Об эффективности предложенных мер говорить еще в целом рано, ввиду того что большая часть правовых актов, принятых во исполнение Стратегии, а в глобальном масштабе цели деятельности ЕС, закрепленной в п. 3 ст. 3 ДЕС, вступили в силу совсем недавно, а некоторые еще в виде проектов. Однако уже можно с уверенностью утверждать, что предпринимаются большие усилия, чтобы обеспечить беспрепятственный онлайн-доступ как бизнес-структур в роли продавцов товаров и поставщиков услуг, так и потребителей к товарам и услугам на территории всего ЕС. Несмотря на большое число различных проблем, внутренний рынок ЕС в эру активного развития цифровых технологий продолжает оставаться моделью для заимствования опыта для других международных экономических интеграционных объединений.

\section{Библиографический список}

Еременко В. И. Директива Евросоюза о реформе авторского права в рамках единого цифрового рынка // ИС. Авторское право и смежные права. 2019. № 11. C. 9-22.

Карихия A. А. Облачные технологии : правовой аспект // Рос. юрид. журнал. 2018. № 6. С. 162-172.

Мюллер-Графббб П.-К. Лиссабонский договор в системе первичного права Европейского союза // Право. Журнал Высшей школы экономики. 2008. № 1. C. 80-99.

Пилипенко А. Н. Франция: к цифровой демократии // Право. Журнал Высшей школы экономики. 2019. № 4. С. 185-207.

Понкин И. В., Редькина А. И. Искусственный интеллект и право интеллектуальной собственности // Интеллектуальное право. Авторское право и смежные права. 2018. № 2. С. 35-44.

Право Европейского союза : учеб. для вузов / под ред. С. Ю. Кашкина. 4-е изд., перераб. и доп. М. : Юрайт, 2019. 172 с.

Ревенко Н. С. Европейский союз на пути к единому цифровому рынку // Мир новой әкономики. 2016. № 2. С. 6-15.

Ролашев Ю. С. Право международных обычаев. М. : Норма : ИНФРА-М, 2020. $144 \mathrm{c}$.

Энтин В. Л. Справедливое вознаграждение как драйвер реформы авторского права в цифровой среде // Современное право. 2019. № 3. С. 53-60. 


\section{Вестник ВГУ. Серия: Право}

Юлашев Ю. М. Правовое регулирование европейского внутреннего рынка // Моск. журнал междунар. права. 2013. № 3 (91). С. 154-176.

A Companion to European Union Law and International Law / Editor(s): Patterson D., Södersten A. John Wiley \& Sons, Inc., 2016. 616 p.

Barnard $C$. The substantive law of the EU. The four freedoms. First edition. Oxford University Press, 2007. 643 p.

Boutayeb C. Droit matériel de l'Union Eropéenne. Libertés de mouvement, espace de concurrence et secteur publique. $4^{\text {e }}$ édition. LDGJ, Lextenso. 2017. $578 \mathrm{p}$.

Dony $M$. Droit de l'Union Européenne. Troisième édition revue et augmentée. Edition de l'Université de Bruxelles: Bruxelles. 2008, 2010. 763 p.

European Union law. Cases and materials / Chalmers D., Davies G. and Monti G. Second edition. Cambridge University Press, 2010. 1011 p.

Mette $M$. The European Digital Single Market Strategy and Related Copyright Law Implications: The Status Que. URL: https://www.whitecase.com/ publications/article/european-digital-single-market-strategy-and-related-copyright-law-implications

Pescatore P. Le droit de l'integration. Emergence d'un phénomène nouveau dans les relations Internationales selon l'expérience des Communautés Européennes, Bruylant. 2005. 320 p.

\section{References}

Eremenko V. I. EU Directive on Copyright Reform in the Single Digital Market // IS. Copyright and associated rights. 2019. № 11. P. 9-22.

Karchiya A. A. Cloud technologies: the legal aspect // Russian Juridical Journal. 2018. № 6. P. 162-172.

Mueller-Count P. K. Treaty of Lisbon in the primary law system of the European Union // Law. Journal of the Higher School of Economics. 2018. № 1. P. 80-99.

Pilipenko A. N. France: to Digital Democracy // Law. Journal of the Higher School of Economics. 2019. № 4. P. 185-207.

Ponkin I. V., Redkina A. I. Artificial intelligence and intellectual property right // Intellectual property. Copyright and associated rights. 2018. № 2. P. 3544.

European Union law / ed. S.Yu. Kashkin. M. : Urait, 2019. 172 p.

266 Revenko N. S. The European Union on the way of the uniform digital marker // The world of new economy. 2016. № 2. P. 6-15.

Romashev Yu. S. The Law of International Customs in the International Law. M. : Norma : INFRA-M, 2020. 144 p.

Yumashev Yu. M. The legal regulation of the European internal market // Moscow Journal of International Law. 2013. № 3 (91). P. 154-176.

Entin V. L. Fair reward as a driver of copyright reform in the digital invirement // Modern Law. 2019. № 3. P. 53-60.

A Companion to European Union Law and International Law / Editors Patterson D., Södersten A. John Wiley \& Sons, Inc. 2016. 616 p.

Barnard C. The substantive law of the EU. The four freedoms. First edition. Oxford University Press, 2007. 643 p. 
Boutayeb C. Droit matériel de l'Union Eropéenne. Libertés de mouvement, espace de concurrence et secteur publique. 4e édition. LDGJ, Lextenso. 2017. $578 \mathrm{p}$.

Dony $M$. Droit de l'Union Européenne. Troisième édition revue et augmentée. Edition de l’Université de Bruxelles: Bruxelles. 2008, 2010. 763 p.

European Union law. Cases and materials / Chalmers D., Davies G. and Monti G. Second edition. Cambridge University Press, 2010. 1011 p.

Mette M. The European Digital Single Market Strategy and Related Copyright Law Implications: The Status Que. URL: https:/www.whitecase.com/ publications/article/european-digital-single-market-strategy-and-related-copyright-law-implications

Pescatore P. Le droit de l'integration. Emergence d'un phénomène nouveau dans les relations Internationales selon l'expérience des Communautés Européennes, Bruylant. 2005. 320 p.

Национальный исследовательский университет "Высшая школа эконоликu»

Постникова Е. В., кандидат юридических наук, доцент Департалента международного права

E-mail: epostnikova@hse.ru
National Research University "Higher School of Economics"

Postnikova E. V., Candidate of Legal Sciences, Associate Professor of the International Law Department

E-mail: epostnikova@hse.ru 